\title{
On the Origin of Consciousness - A Personal Experience on the Interaction of Mind and Body
}

\author{
Borje Peratt
}

Humanism and Knowledge Academy, Sweden

Copyright $(\mathcal{C} 2016$ by authors, all rights reserved. Authors agree that this article remains permanently open access under the terms of the Creative Commons Attribution License 4.0 International License

\begin{abstract}
The title is, of course, an allusion to Darwin's classic book "On the Origin of Species." Here we are concerned with the question of whether there is actually an origin of consciousness or if consciousness is eternal and its availability limited by physical senses. A car crash in 1987 opened my mind to the possibility of consciousness existing independent of the senses i.e. independent of the brain and body. The circumstances surrounding the accident involve a variety of extrasensory perceptions, which, up to that time, I had ignored because of my scepticism. The accident almost cost me my life and led to a long period of convalescence reflecting on what had happened. My documentation of the resultant experiences made it plausible for me to conclude that extrasensory sources of information were active even before the crash and also that these senses seemed to be boosted during the years that followed. In order to understand what had happened, I started to investigate my own experiences and then began to search to see if there were other people reporting similar experiences. It initiated what was to become research for more than twenty years. This really took off when the Internet and its search engines enabled data collection. The method based on Grounded Theory led to proto-scientific theories, published in book form in Swedish.
\end{abstract}

Keywords Consciousness, Near-death Experiences, NDE, Transpersonal, Extrasensory Perception

\section{Introduction}

1.1. A car crash in 1987 profoundly changed my view of consciousness. The healing process also produced experiences that left me pondering as to whether there was something beyond the body's accredited five senses.[1][2]

The accident, which destroyed our plans for a long trip, instead led to an inner expedition that fundamentally changed my view of mind and consciousness. The cliché that "it is not the destination but the journey that is important" was given a new meaning. Driving off the road gave me the opportunity to consider a new field of research. The circumstances of the crash gave rise to many questions.

It was early one Saturday morning and I was standing with my hockey bag in the hall. The rest of the family was asleep. I moved carefully in the silent house and walked towards the front door but didn't even reach the inner door. It was as if a heavy iron barrier stopped me. Obviously there wasn't one, yet something prevented me from moving forward. Confused, I dropped the bag and wondered what, in fact, had stopped me. No, there was nothing there. I picked up the bag and walked towards the door. Bang! Stopped again. What on earth is this? I stood for a while and wondered if the resistance was within me. Then I forced my way through this invisible barrier, opened the front door and went out on to the steps. It was still dark, the only light coming from some Christmas stars in a neighbour's darkened window. "Borje!" Someone was calling me. I put the bag down and went into the house again. No, everyone was asleep. I went back out, picked up the bag and headed down the steps. "Borje!" "What's going on?" It was still dark in all the neighbouring houses. Whoever was trying to fool me called out again as I ignored the voice and continued walking towards the car. I threw the bag into the car and started the Range Rover, its eight cylinders roaring into life. In the winter, a car like this feels safe and strong. A few minutes later it would plough a "firebreak" in the forest. Just as the car flew into the woods, I remembered the previous night's dream and realised why my whole being had warned me that I should not go out that morning. I awoke to the sound of distant voices. I was in the passenger seat, my head against the floor; I felt the life pouring out of me. With a desperate effort, I managed to reach the car phone. At that time, mobile phones were rare and very expensive. Now it came in handy. I saw that the car was pretty far down in the ravine and up on the road stood an ambulance, its blue lights flashing. A police car left the scene and headed towards our home.

I managed to press the speed dial number for home and a sleepy wife answered. I could not make a sound. She 
said "hello" a few times then hung up. I called again and she answered, still tired. With great effort I managed to say: "There's been an accident." Ritva asked, shocked, "Where are you?" In the background, she could hear sirens. I passed out again and woke up to the sound of the paramedic's voice. It was a fast drive to the nearby hospital. I was moved to the ultrasound, where I said: "Spleen," the operator nodded. Before I passed out, I managed to say to Ritva "No blood." That was also a message from the previous night's dream. An emergency alarm went off and Ritva explained to the surgeon that I did not want a blood transfusion. "OK," said the doctors, "then we need to hurry." Shortly afterwards, it was found that the hospital's blood plasma, imported from Denmark, had been infected with Hepatitis C, which, because of my inherited blood disease, would probably have caused liver cancer.

Prior to the crash, I had ignored several "warnings." Now I wanted to investigate discreetly the strange phenomena that had preceded the accident and some that occurred afterwards.

First of all, the five senses, as Aristotle established them in ancient times, are not enough to explain what I perceived. So I started seeking other explanations, others senses, other ways of communicating.

Were there methods of communication and frequencies in nature that I had not heard of? What I found was that there were animals communicating by changing skin-colour or using skin-colour change as camouflage. Others were communicating using subsonic frequencies that travel vast distances, with significant information to animals that can perceive and identify these messages, some, such as elephants, by locking out the ear, perceiving and interpreting such messages at least partly in the body. For a while, this distracted me from looking into ESP. I followed my curiosity to see if the brain had senses other than the five, or if there was something else in the brain that could explain the possibility of precognition, for example. (To know something before it happens although nothing indicates it.) I narrowed this plan of research and defined it as a "brain consciousness" separated from a "body consciousness," having its own senses.

Over the years it became obvious that scientific research on consciousness was often about "brain consciousness." A reductionist materialistic view upon this may believe that this is all there is. However, my opinion is that there are at least two other distinct forms of consciousness.

\section{2. "ECO-Senses and Body Consciousness"}

The hypothesis emerged of a form of consciousness enabled by somatically-based original senses that I termed "ECO senses: Emotion - Communication - Orientation."

Moving on from the ordinary five senses, "Emotion" is, in my hypothesis, the sixth sense originating in the body and the source of the ability to distinguish between "beneficial" and "non-beneficial" feelings. In order not to confuse inner feelings with the physical skin or sense of touch, I have therefore chosen to call it "Emotion Sense." Ideally, I would also just like to use the term "skin sense" or "sense of touch" as one of several "physical senses" to avoid confusion with "emotion sense."

The seventh sense, "Communication sense," not only perceives but also transmits information and prepares information. In addition to interpersonal functions between individuals it has an internal role when it comes to communication between cells using neurotransmitters. This internal communication can take the form of signals and reflexes as a type of communication. I also use the term "communication" when it comes to internal psychological reflections and commands to oneself, paraphrasing Ericsson's slogan "It's all about communication."

The Eight sense is "Orientation sense." One hypothesis is that the orientation of the mind is there from the beginning and has its origin in the first headless organisms. Its role in the body is to locate the body's internal need for measures and arrange to send the right measure to the right organ and body part. Orientation sense also has great importance for orientation in the surroundings. A floating organism could perceive changes of water pressure, localise favourable and unfavourable levels of the sea and from this start a possible evolutionary process where the orientation of the surroundings was developed and refined. Some organisms have, since the dawn of life, developed navigational qualities involving magnetism and, later, genetically inherited memories of terrain and space. To handle the environment, they needed the senses of smell and vision. With an increasingly complex brain, the organism can process models or map representations of reality. This insight intermediary mind interacts with the parts of the brain that record, process and store memories.

In summary, physical orientation is about finding the right memory image, locating the right direction and identifying the correct path.

\section{3. "Brain Consciousness"}

The nervous system consists of the peripheral nervous system, which is important for body awareness, the central nervous system via the spinal cord and the brain, which provides the brain consciousness. A paralysed body only allows limited body awareness. A defective brain gives a distorted brain consciousness that can affect personality. Instinctive bodily reactions and body awareness can still have independent existence.

Physical "elementary" senses, such as vision, hearing, smell and taste, not only affect the brain's consciousness but also the body. The smell of food can make us hungry. The sight of something unpleasant can make us nauseous.

One question concerns how brain consciousness can affect physical ability. The issue is not the theme of this article but is part of research which relates to the potency of conscious and unconscious mental attitude. The notion of possibilities of mental focus has long been used in sports and mental training and today is as important as physical 
exercise if an athlete wants to achieve top results. "Are you - a result of the past? or a cause for the future?" It is quota from the Swedish professor Lars Eric Uneståhl who has a lifelong record of studies in the field of mental training. [3]

The brain also provides an automatic reflex communication to different parts of the body; basal ganglia serve as a feedback system and ensure that movement is smooth and well coordinated. Basal ganglia also have a filtering function that allows movements that are not fully completed and thereby allow the brain to draw conclusions about what is favourable and not favourable. The mammalian brain is composed of parts that gradually build up during evolution. However, before the head emerged, the body's skin perception was handled by the nervous system in the body.

This precursor to the brain is situated near the heart and the mouth, which later became the communication centre. Thus we can assume that what later became the chest and neck have harboured the methods of communication.

The human brain's frontal lobes' logical qualities and speech centre added the ability to express sound and articulate qualified language; thus life could refine and cultivate social interaction. At the same time, we should remember that social ability is linked to the amygdala, which is, from an evolutionary perspective, a much earlier part of the brain. This part interacts with the hypothalamus and the "survival centre." A safe social interaction enhances this part of the brain and increases the feeling of well-being, which affects health in a positive manner. Such a link is not unique to humans but is an essential part within many animals.

Studies of foetal and child development provide a picture of how brain systems have been built and function. According to the Finnish brain researcher Matti Bergström, development begins deep down in the core of the trunk and around the forming concentric rings of neural pathways, as the individual grows. Thus, a disordered core surrounded by circular reflex pathways becomes increasingly ordered. Bergström tells in a mail conversation with me related in the second book of Origin of Consciousness:[2] "Our brain is apparently a rendezvous between disorder and order, between chaos and knowledge ... a system with two poles with completely opposite operations: an entropic kernel that sends unordered signals into the brain and a negentropic outer shell that sends in arranged signals ... When life moved from the sea to the land, it came into a world with "steeper energy gradients" (an environment with larger and more violent conflicts between hot and cold, light and dark, storm and calm). The living organism's response to the emergence of increasingly steep energy gradients in our drying planet's nature was that skin, the boundary layer, developed into a communication system built of neurons, with the task of mediating between vegetative tissue and surroundings. There was formed a brain ... with two adjacent surroundings, the internal and external."

There is also research based on the hypothesis that it is possible to control even environment using "thought power."
One use is to give disabled people a method whereby they can control with thought. During the 1970s, Oliver Spencer, Bionics Research Laboratory, Colorado Springs, got worldwide attention through his work to rebuild Steve Austin, a colonel in the US Air Force who had been severely injured in a serious plane crash ("The Six Million Dollar Man," 1973). Merely the thought of a body action is used to control the mechanics of body parts. The Chinese researcher Bin He, Doctor of Bioelectrical Engineering, has taken this a step further. He mapped the initial path from thought to action, i.e. what happens in a purely neurological context from when the individual visualises a movement until the technical tool performs the intended action. The thought to clench a fist activates specific neurons in the motor cortex, which then produce electrical signals which in turn leads to the technical communication-controlled robot performing its pre-arranged movement. Within this area there are several ongoing projects that will give disabled people opportunities to cope with torque which was hitherto impossible. This area can be classified as Mind over mechanical - or Thought controlled bionics, having artificial body parts, especially electro mechanical ones.[4]

\subsection{Emotions}

Dr Charles W. Super wrote in "The Popular Science Monthly" (1914) an article called Science and Poetry: "The scientist always regards emotion as a disturbing factor. It prevents him seeing objects as they are. Emotion interferes with clarity of vision and distinctness."[5]

Emotions have long been regarded as disturbing by the natural sciences academies since you cannot study emotions as easily as other "logical" phenomenon. Darwin emphasised the importance of emotional expression for survival and adaptation, and his "Emotional Expression in Humans and Animals" from 1872 is considered as launching modern emotion research. However, interest in the book about emotions abated pretty quickly. René Descartes published Passions of the Soul (1649) dealing with emotions. It also quickly fell into oblivion, as opposed to his idea of "I think therefore I am."

The Scottish philosopher David Hume (1711-1766) argued that without emotions ("passions") man was completely inactive, since reason itself only "is" and man need to be "passion's slave" to even function.

This may also support a theory of a "Life Intelligence" including IQ and EQ.

Could emotion have the fundamental responsibility for all communication in the body and between other beings in nature?

In a way both Nobel laureate Roger Sperry's split brain theory of the resources of left and right brain[6], as well as Robert Cloninger's molecular biological temperament models[7] and physicists' description of quantum physics' smallest particles, the quarks (especially the charm quark[8]), may confirm Hume's idea. Without emotions we may lose the sense of connection, empathy and togetherness. The 
naming of the "charm" quark and the "strange" quark indicates that the smallest particles have a behaviour that is reported to act accordingly to the researchers' expectations. [9] This means that the smallest particle may be influenced by thoughts, emotions and expectations. The Mind interacts, communicates and creates.

Dopamine, serotonin, oxytocin and endorphins are the quartet responsible for our happiness, according to Thai Nguyen, lifestyle guru. "Many events can trigger these neurotransmitters but rather than being in the passenger seat, there are ways we can intentionally cause them to flow. Being in a positive state has significant impact on our motivation, productivity and wellbeing."[10] This isn't a new idea: many have said it before. What it means is that man has the ability to use internal communication, exchanging "brain and body consciousness" that may enhance health, wellbeing and performance capacity.

A placebo activates a mental "reward system" that produces endorphins: painkilling morphine-like substances. When this self-healing mechanism is enabled for a specific problem, it seems to act faster. Thus, the ability to heal itself is tied to body consciousness and the emotional and mental capacity of the brain.

\subsection{Life Intelligence}

My research for explanation of extraordinary experiences of perception (ESP) led to The Origin of Consciousness and The Origin of Intelligence. The latter was also influenced by the experiences of a car-crash-damaged body in its healing process. Actually sensing the process made me think of organs and cells "communicating" and also that my own mentality could possibly have an influence by a positive attitude to this healing process. So I talked to my body and learned how to cope with the pain, using fewer and fewer painkillers. This was in 1988, before Nguyen was born; what was new to me was that I could actually see the healing process as a film. At the time, of course, I considered it to be imaginary. Later, when I also dealt with methods of healing, I found that it wasn't just imagination. This suggested a new concept: the possibility of different forms or dimensions of intelligences. It also led to thoughts on the beginning, where it all started.

\subsection{Evolution}

The belief in natural selection is too limited to explain evolution; you take the power out of life's own ability to change and adapt. Therefore, the Darwinian addition is important: "It is not the strongest that survive but those who have the ability to adapt." Darwin's explanation opens up the possibility of change based on intent and purpose. Let us assume a Life-Intelligence in each creature throughout evolution that not only adapts to circumstances but may also have the option to change them. The constructive opportunity may lie in "the vision of the favourable."

Presumably, those who have talked about the power of thought come close to an explanation of the driving force that is also in the process of evolution.

John Grandy, general practitioner, Watertown, New York, studying the origins of human consciousness: Results show that the DNA molecule indirectly has its own consciousness, which provides the conditions for all other levels of consciousness. A constant interaction with the environment increases the complexity of this molecular level up to the primate level. DNA consciousness is thus a possible source of the onset of a neurological consciousness. Consciousness is then a part of evolution and exists simultaneously at all levels, from our smallest building blocks of quarks (quantum) to us humans. [11] Grandy's conclusion that DNA can explain all dimensions of consciousness may be wrong but his research supports the idea that physical life is run by a sort of life-navigator that tests various conditions. Grandy then indirectly supports the idea of an organism seeking favourable living conditions. Let's take a deep breath and imagine that the body asks a question: what may work for it to improve? And there is a mutation: considering this as random does not take into account that possibly there could be an intention behind a will to change.

What has emerged as an issue here is whether there is a stage before the idea, something that is subtler than a desire and more like a premonition. "What if...?"

The overarching question is therefore: what makes it possible for anyone to create a future that is beneficial? Is it possible that this ability is in every living being? That could mean that life-changing evolution is "delegated" to the smallest living organism. On one level it seems completely random but on another level it seems obviously coordinated and intelligent, especially when groups of organisms organise and behave as one.

\subsection{Cell Intelligence}

Cellular information may have some support in studies on cell behaviour. Cognition is usually regarded as the brain's working area, with various features that are important for attention, memory, learning, language, decision-making and problem-solving. However, these abilities are not limited just to humans or animals. Similar functions are presented through the unicellular protist slime mold Physarum polycephalum as mentioned earlier. As a unicellular protist can interact and be able to march in unison it has a kind of rhythmic skill. This provides evidence that functions normally handled by a brain may also be processed by a body-mind function, which performs in micro-organisms and in the smallest cell.

This may lead to a hypothesis of possible cell-intelligence and body-consciousness relating to the exchange of information within the body and also interpersonally between individuals.

It is not only possible evidence for "central senses" of the headless body but also that each cell can have "body awareness." This approach can be considered controversial in the conventional medical world, in giving the individual 
cell a consciousness and intelligence. However, even in this science, things start to happen. Sondra Barrett, researcher on cell biochemistry, reached a similar conclusion about the body's inner intelligence. [12] Guenter Albrecht-Buehler, Professor of cell and molecular biology, has attempted to analyse the "chain of command" of the cell's movement. According to this work, the "brain" of the cell (= centrosome) collects visual information with its built-in "eyes" (centrioles), sending commands along the "nerves" (microtubules) to "muscles" (autonomous cortical units called micro-plastics) that initiate the molecular interactions and that ultimately lead to various manoeuvres. The cells can form different organs, using different sets of genes and special genetic programmes, in different cell types. [13]

When cells divide, the new cells remember which cell type they belong to and use the correct genetic programme. Even if Buehler is not considered as studying consciousness, he shows how cells orientate themselves, evaluate their status and communicate. Evaluation requires a kind of emotion: "good or bad" so even if it is reflexive it is also available for quality discernment. The origin of central senses can thus be based on Buehler's description of the cytoplasm functions placed in the cell. This may explain why the cells are clustered in specific concentration areas with specific tasks. Each small cell also has its own cell memory, which can have unexpected and remarkable implications in transplantation. The work of Guenter Albrecht-Buehler and Robert Laughlin at Northwestern University Medical School, Chicago, might give some further clues on the subject of cell intelligence. [14] It should, however, be pointed out that I make no claim to possess the scientific competence to critically evaluate these findings.

\subsection{Search of a Mind-body Intelligence}

Researches in the area of brain and body consciousness didn't give me any explanation for ESP experiences. Rather, I had to accept that those experiences were independent of physical and biological controls. So I created the term "Independent Consciousness" as a hypothesis to find some studies in the area of a consciousness outside the body, a mind-body intelligence. Much later, I found Larry Dossey's explanation, which he called "Non-Local-Mind."[15] Dossey also introduced a theory that explained how healing could work at a distance.

I had discovered a possible mental influence of the healing process in my own body after the car crash. When I later tried it on others and found out that it might have effect even on a distance it certainly awoke an urge to search for education. I took some courses in healing techniques and also found out that I could "see with my hands."

A medical clinic with physicians and nurses who were interested in the phenomena of healing and also other transpersonal phenomena gave an opportunity to examine such techniques. I carried out 15 clinical experiments on my awoken "gift" under clinical surveillance. I was presented with several volunteers in the research on phenomena such as healing, clairvoyance and telepathy. When I met a test subject I didn't know what the problem was; I wasn't given any information about their condition. Yet I could locate a faulty organ, see it and not only describe it but also draw a picture of it. One spectacular result of this was when I could "see" (clairvoyance) the spine and then locate a problem disc, drawing a sketch of it, then be shown an x-ray of the disc looking exactly like my drawing. Still very sceptical about the whole thing, I had to accept the fact that very often I could not only tell what was wrong but also help.

To avoid any form of "cold reading" I often had the patient's back to me and the patient might be a distance of 5 metres or more away. The team controlling the experiment could then say: "Ocular observation shows a change in the area where the patient suffers pain..."

In searching for other studies on the subject, I found "Shaman Wisdom - Shaman Healing" about Native American healing technique. [16] In a Christian religious context Witness Lee has given examples of a belief in a divine consciousness trying to explain relevant contents from the bible. [17] They are all taking an independent consciousness for granted referring to a holy spirit and that the obvious way to connect is through chanting, prayer and contemplation. I do not deny such religious methods, and have great respect for these beliefs, but they do not help me to understand how it works.

I assumed early that there must be another sense, previously unexplained, which is active when paranormal experiences occur. I assumed that each cell had its intelligence, emotions and methods of communication. This is now beginning to be recognised as a possibility even by those researching cell structure and communication. However, the possibility of cell communication cannot explain how my mind could "see" organs and correctly diagnose without medical knowledge. Was this a previously unknown sense that interacted with the cells of the body?

This led to a more spectacular explanation: could it involve " independent senses" which are not dependent on physical senses? One such sense is assumed to be clear-sense where one perceives through inner vision (clairvoyance and clairaudience). Yet that does not explain how I obtained knowledge new to me. Is there also an independent mind that instantly has access to all kinds of knowledge? If so, who or what conveys the correct diagnosis?

Studies of patients diagnosed as clinically brain-dead led to a further track. These patients had returned to life and talked about what nurses and doctors had said and done while they were unconscious and none of the physical senses were functioning. I began studying transpersonal phenomena and found that some sceptics' bully-like treatment of this science could frighten anyone into silence. Yet the questions persisted and more than 20 years of research, with myself as one of the objects of study, have led to proposals for a new division of senses. The discovery of others' experiences reassured me that I was not alone and that meant an understanding of different kinds of senses. Some experiences 
related by others were in a dimension other than space-time and independent of time and place.

\subsection{Other Cases Reported in a Scientific Manner}

Googling: "car crash; accident; near death experience" produces several stories. However, it is difficult to find similar cases described in a scientific manner; therefore, I only compare three others' unique cases and unique experiences which have a scientific approach but according to Grounded Theory these are not my experiences and I can not guarantee the veracity just shortly present others experiences. As they are described they are all lead to the same conclusion: there is an "independent consciousness."

\section{Case 1}

Dr. Jill Bolte Taylor is a Harvard-trained neuro-anatomist specialising in post-mortem examination of humans. In her work she cuts up the brains of dead people to look for the neurological causes of serious mental illness. She is thus very familiar with what happens in strokes. On the morning of $10^{\text {th }}$ December, 1996, a blood vessel exploded in 37 -year-old Jill's brain. She woke up to find that she had had a massive stroke, a severe bleeding in her brain. Her immediate thought was "Oh my gosh, I've had a stroke!" This was quickly followed by "Wow, this is so cool!" As a curious neuro-anatomist, she was fascinated by being able to observe how her own mind systematically deteriorated, to the point where, four hours later, she was unable to walk, speak, read, write or recall any of her life. This meant that the dependent consciousness in what I call the "existential hub" (where the entire memory bank is) was knocked out. The most fascinating part of Jill's story is her subjective experience during and after the stroke. With the left hemisphere eliminated, she experienced, without ego and without physical senses, happiness and feeling at one with the universe. Jill's stroke resulted in engagement with the physical world being cut off. It is defined by our language, and analytical concepts of reality, as "me" and "not me." From an outside perspective, she lost abilities such as language, orientation and critical analysis, which made her unable to function normally. However inside her perspective, it relieved her mind and allowed her to experience reality in a totally new way, open and intuitive. She lived in what she calls the "right here, right now awareness," a euphoric explosion of stimuli, no sense of past or future life, every moment fresh and undefined. She said that she was linked to the universe. "As the language centres in my left hemisphere grew increasingly silent and I became detached from the memories of my life, I was comforted by an expanding sense of grace." (p. 41) In the book "My Stroke of Insight" (2009), she describes the neural circuits of bliss in the brain's right hemisphere. When Jill was better, the liberation of the right hemisphere could launch a whole new flow of creativity. After recovery, she became both an artist and scientist and created new images of brains. Jill Bolte said on her recovery: "I believed in the plasticity of my brain - its ability to repair, replace and retrain its neural circuitry. In addition, thanks to my academic training, I had a "roadmap" to understand how my brain cells needed to be treated in order for them to recover." (Pp. 35-36)[18]

\section{Case 2}

Dr. Eben Alexander is a highly trained Harvard neuro-surgeon. He knew that NDEs felt real but was of the opinion that the experiences were simply fantasies produced by brains under extreme stress. Then Dr. Alexander's own brain was affected by a rare illness. The part of the brain that controls thought and emotion (and in essence makes us human) shut down completely. For seven days he lay in a coma. Then, as his doctors considered stopping treatment, Alexander's eyes suddenly opened. He had come back.

Dr. Alexander wrote in his book Proof of Heaven: "Misleading concepts that focus on reductive materialism have kept us in the dark about the true nature of the human soul and its integral part in our evolution as spiritual beings."

The old paradigm of 'birth to death' represents an outdated concept that is woefully inadequate in defining the unfolding reality of expanded awareness," he stated in an interview with Waking Times. "Materialist science is at the end of its days, as most scientists are changing their views. The old concepts are soon to be relegated to the same dust-bin as 'the earth is flat,' as we develop a more mature understanding and transcend old beliefs." [19]

\section{Case 3}

Tony Cicoria has a history reminiscent of mine. I was not hit by a lightening bolt but a car crash and my visions of the music came much later after the accident, so the connection is not as obvious. In my case, there may be other factors to be considered. My history of near-death experiences is different. However, we share the Out-of-Body Experience (OBE) and the sense of "new music" coming from outside our own creativity. [20] Oliver Sacks, a professor of neurology at the N.Y.U. School of Medicine, has written Cicoria's history and one article is quoted.

Tony Cicoria was forty-two, a fit former college football player who had become a well-regarded orthopaedic surgeon in upstate New York. In 1994, he was participating in a family gathering and needed to make a phone call using a pay phone outside the pavilion. He says:

"I was talking to my mother on the phone. There was a little bit of rain, thunder in the distance. My mother hung up. The phone was a foot away from where I was standing when I got struck. I remember a flash of light coming out of the phone. It hit me in the face. Next thing I remember, I was flying backwards."- "I was flying forwards. Bewildered. I looked around. I saw my own body on the ground. I said to myself, 'Oh shit, I'm dead.' I saw people converging on the body. I saw a woman - she had been waiting to use the phone right behind me-position herself over my body, give it CPR. . . . I floated up the stairs - my consciousness came with me. I saw my kids, had the realization that they would be O.K. Then I was surrounded by a bluish-white light ... an 
enormous feeling of well-being and peace. The highest and lowest points of my life raced by me. I had the perception of accelerating, being drawn up. ... There was speed and direction. Then, as I was saying to myself, "This is the most glorious feeling I have ever had'-slam! I was back.”

Cicoria knew that he was back in his own body because he felt pain - pain from the burns on his face and on his left foot, where the electrical charge had entered and exited - and, he realized, "only bodies have pain." He wanted to go back, he wanted to tell the woman to stop giving him CPR, to let him go. But it was too late- he was firmly back among the living. After a minute or two, when he could speak, he said, "It's O.K.-I'm a doctor!" The woman, who turned out to be an intensive-care-unit nurse, replied, "A few minutes ago, you weren't." [21][22]

\subsection{Reflecting on Cases, Experiences and Other Research}

Jill Bolte had an internal view of the cells in the brain that can be compared with how I had a view of the broken parts of my body and could perhaps influence the healing by "talking" to these parts.

One question is whether such communication can also influence the environment. In 1909, Jung visited his mentor Sigmund Freud in Vienna and asked him about his stance on supernatural phenomena. Freud dismissed the idea but then something strange happened. Jung tells:

"While Freud was arguing in his usual manner, I had a strange experience. It was as if my diaphragm was made of iron and was red hot. At the same moment, we heard a bang, well a loud boom, from the bookcase standing right next to us. We jumped in fright, afraid that the bookcase would tip over on to us.

I said to Freud: 'This is an example of a catalytic exteriorisation phenomenon.'[23] - 'Oh come, come,' he replied; 'That is absolute rubbish!' - 'It is not,' I replied. 'You are mistaken, Professor. And to prove my point I now predict that in a little while there will be another loud bang!' I had barely finished speaking when a similar explosion resounded in the bookcase. To this day, I do not know what gave me this certainty. Yet I knew beyond all doubt that another bang would come. Freud just stared at me, aghast. I do not know what he thought or what his look meant. In any case, the incident caused him to distrust me and I had a feeling that I had done him some harm. We never discussed the matter again."

I could understand Freud's rationalisation. It would take several years of my own experiences before I began to read about paranormal phenomena. The more I read, the more airy-fairy I found it. "So many gullible people out there!" Oh yes, there were those who believed although they had not had any personal experience. This seemed a mystery to me. Did they have any inkling or were they just easily fooled or influenced by wishful thinking? On the other hand, I also found sceptics even more rigid than me who would not believe in any such rubbish as transpersonal experience.
When trying to explore those phenomena, such scientists may find themselves in a situation like the Inquisition and witch-hunting, with debunkers like James Randi engineering fraud and sabotage of such studies to ridicule them. [24][25]

The Stargate Project was a CIA-initiated study on remote viewing conducted at Stanford Research Institute in 1995. "Regardless of one's a priori position, an unimpassioned observer cannot help but attest to the following fact. Despite the ambiguities inherent in the type of exploration covered in these programs, the integrated results appear to provide -unequivocal evidence of a human capacity to access events remote in space and time, however falteringly, by some cognitive process not yet understood. My years of involvement as a research manager in these programs have left me with the conviction that this fact must be taken into account in any attempt to develop an unbiased picture of the structure of reality." (Puthoff, $\mathrm{PhD})[26]$

One assumption is that of a clear mind leaving the body in what is known as an "out of body experience" (OBE). It involves clairvoyance, boundless, timeless and unlimited by distance and time scales.

With these practical experiments, clinical studies and findings of others with similar experiences came more questions. The project grew and became more scientifically demanding. The issues of consciousness meant examining whether there were different kinds of consciousness that could interact and whether an independent consciousness was completely independent of time and place but could affect the physical life that obviously was governed by time and space. Einstein's four-dimensional theory was then of limited help. I needed an expanded theory. Jean Gebser (1905-1973), a Preussian-born German philosopher, did a structure of human consciousness similar to my ideas. Finally I reached a theory of "On the Origin of Consciousness" but that is not the subject of this article.

\section{Objectives}

Is there a need for a new view of consciousness and the senses? My experiences led me to propose three categories, which may revise our traditional view of perception and consciousness.

1) The so-called "Five physical senses" which are fundamental. I call them Elementary. They are necessary for "brain consciousness."

2) Three ECO-senses: Emotion, Communication and Orientation. I call them "Central senses." They originate in the body and give a "body consciousness."

3) Four "independent senses" that are independent of the body. In areas within so-called paranormal phenomena, terms such as Clair Sense and Clair Voyance are being used.

Can such senses also take over the consciousness when the brain is in a dream state, an unconscious or radically reduced level of activity such as coma, or clinical brain death? It suggests possible states of consciousness separate from the brain and body what I call "Independent 
consciousness."

Precognition and lucid dreams offer perhaps the most difficult challenge posed to causal thinking (cause and effect). This is the notion that a non-predictable effect can precede as a vision before it actually happens. Is it possible to think, feel or perceive what is to come, though no objective signals indicate future events? Is it possible to change destiny by affecting the probable cause? Could there be evidence that allows this reversal? If so, how does one explain it?

To form a theory of the origin of consciousness we probably need to consider various states and dimensions.

\section{Materials and Methods}

\subsection{Credibility Problems}

There are reasons to be sceptical about the idea that minds can exist independent of normal bodily processes. Anyone who "clear sees" for the first time may try to suppress the "imaginings."

There is also a critical and widespread distrust of phenomena and mediumship.

For these reasons, I applied the method of Grounded Theory to describe and try to clarify my own experiences.

\subsection{Grounded Theory}

Grounded Theory (GT) is a research method developed in medical sociology but used in other fields such as education. Empirical research, with observations of reality, is the source of knowledge. A GT study will primarily be based on the researcher. Personal observations are the source of my knowledge. Scientific literature is built on the research project, based on the issues that arise. It has, in my case, brought an increasingly complex picture comparing my own experiences with the findings of others. Existing theories and hypotheses previously known from literature should be ignored at the beginning of investigation. At the end of 1988 I had no knowledge of what had happened to me and therefore subsequently no access to theories or studies. At that time, there was no Internet so I just documented my experiences in a diary. I tried to formulate hypotheses based on specific data and carried out experiments and searched to explain them (induction).

\subsection{The Hypothesis of a Consciousness Regardless of Time and Space}

In the beginning it was difficult to draw reasonable conclusions from the hypothesis of an independent consciousness. It became obvious to me that there was a need to form a theory that could explain the possibility of a "travelling mind regardless of time and space." A possible explanation came from a surprising direction, Albert Einstein.
Surprisingly to both scientists and non-scientists, Albert Einstein suggested that past, present and future exist simultaneously. Einstein (1952): In the four-dimensional structure [space-time] there are no longer any sectors [time-divisions] that objectively represent "now." The terms "happened" and "going to happen" cannot entirely be abandoned but it is still complicated. It appears, therefore, more natural to think of physical reality as a four-dimensional existence, instead of, as hitherto, the evolution of a three-dimensional existence.

\subsection{The Problems in Defining Concepts}

The method is a way to create an understanding of perhaps a new concept also enabling new terms needed to fully understand the development of the hypothesis to clarify and define a proto-scientific theory. To really understand what is meant, it is important to understand the meanings of words and their implication. In 2010 the first part of Origin of Consciousness was sent on peer review [27] defining the concept of an "Independent Consciousness" [28]. At that time the reviewer found no references in English literature although the idea of such a mind since long is considered a fact in most religions and philosophical beliefs such as Buddhism. But the specific term "Independent Consciousness" had so far not been used or spread. 2013 I expressed its definition and content on a Swedish alternative to Wikipedia called Vetapedia [29] since the Swedish Wikipedia was and still is controlled by the skeptics Wikipedia-guerilla manipulating articles related to science emphasizes biological naturalism as the basis of consciousness. The term was then used in 2014 on in a Swedish Wikipedia article about consciousness but in relation to behaviourism: "The solution is to eliminate the idea of an interior mental life (and hence an ontologically independent mind) altogether and focus instead on the description of observable behavior". In its context, it can be seen as an example of aggressive exclusion of the theory of an independent mind. This perspective is also presented by John Searle [30] stuck in in the brain as a tool or what I call "elemental mind" only accepting the biological prespectiv, the perception of the five physical senses and its brain-processes.

Since 2014 the term independent consciousness (in English) is widely spread on Google and is accepted as an expression of a consciousness not dependent of the brain or the physical body.

An independent consciousness enables a range of transpersonal experiences such as out of body experience (OBE) and precognition. Sometimes precognition is misunderstood as intuition.

The concept of intuition is according to Dreyfus [31] a skill we use in everyday life and in particular when we are at our best. It is sometimes misunderstood as a "fuzzy" concept because it is confused with gut feeling. From a strictly behavioural science perspective, intuition is an extraordinary natural skill. The best fighter pilots, the most 
skilled doctors, chess masters and many others are guided by their intuition. Intuition is based on utilising acquired experience and knowledge. Intuition surveys the situation with lightning speed, makes clever shortcuts and takes decisive positive measures. [32]

\section{Results}

After studying and meeting with different directions of spirituality, I have chosen to be circumspect with such results except from the NDE cases displayed. There is great knowledge to be gained on the basis of transpersonal perspective from these cases. They provide valuable knowledge and experiences that could provide support for the theory of independent mind.

Since there is an interest in mental ability, some of the research may confirm an assumption of "the power of the mind."

\subsection{Putting Myself to the Test}

It turned out that I probably had several of the extra-sensory senses being used by people involved in psychic activities and mediumship. Examples of these are clairsentience being used for Remote Viewing; telepathy talking with living people at a distance not using any technical facilities; mediumship - talking to dead people transmitting specific information of which I had no previous knowledge. An example of precognition is when I felt deep sorrow for the loss of a person and nothing indicated that this person would die that very day. It was later confirmed that she had passed away at the time I was given and had also forewarned her sceptical relative. Although this was alarming and nerve-wracking, I was so certain that I had no hesitation saying it.

The deceased lived in another country overseas, so it took some time to travel to meet her children. All the way there she was talking to me from "the other side" about how she wanted her children to be taken care of. Knowing that they would be very sceptical, I was given facts about what they did the morning we met. This unlikely knowledge convinced them. So I could tell the teenage son not to do something which only he knew about, and also tell the daughter to do something that she had been resisting and which only she knew about.

I am still very sceptical about it all, almost frightened. Messages using Extra Sensory Perception nowadays seem to occur whithout any pattern. For a while I frequently had visions that were not particularly pleasant. Some of them I used as creative ideas, not believing they were anything other than imagination. In the spring of 1994, I produced a slideshow that became a kind of prediction about the sinking of the ferry Estonia. The original text came from an employee of the Board of Civil Emergency Preparedness (OCB). The Supply Commission would use the programme for an emergency drill. The Estonia disaster occurred on $28^{\text {th }}$
September 1994. The similarity with the slideshow was frightening.

Another powerful vision, in 2002, took the form of a remarkably lucid dream. It showed a huge wave that swept across the countryside, as a result of an earthquake in the ocean in Asia. In the dream, I was prompted to write down and share the horrific scenario. The story was distributed to a limited group, whose task was to pre-pray for the children (from around the world) who would be affected. I did not know then that it was called a tsunami, much less that such giant waves could be formed. The nightmare story is astonishingly similar to the actual course of events. In my vision, the disaster took place near Indonesia, the area in the Indian Ocean that was hit by an earthquake that triggered the tsunami of Christmas 2004.

Here I would add a more personal event associated with a mediumship training course that I attended for the first time. I arrived late to the session where all the participants were unknown to me. Therefore I did not participate in the initial introduction of the members nor did I introduce myself. At this meeting with people of whom I knew nothing, out of the blue I got three maiden names, one of which was an unusual double-barrelled name. When it was my turn I said the names and a woman confirmed that she "knows who these girls are, three sisters." Then I said that I saw one girl, who I named, in a canoe that turned upside-down, with her ending up in a panic underwater. The woman declared confidently, "Ah, she is not interested in such adventures." I suggested that she should still contact her. She contacted her friend and found out that she had just bought a canoe and that summer planned to paddle around the archipelago on her vacation. The girl was more upset than happy at the warning: "Now that I finally got the courage to go on an adventure, you bring me such nonsense!" The friend still chose not to pursue the canoe holiday. Instead, she reportedly had another "wonderful holiday." Such stories are in natural science considered anecdotal and of less value as evidence. Therefore, it is particularly important to strengthen human sciences and humanistic psychology, per se, and especially transpersonal psychology, which takes advantage of unique and individual events, and considers what I call "one case validation."

Trans-empirical consciousness goes beyond our experience, beyond what is considered possible to prove and it is possibly even a description of a spiritual consciousness. Lothar Schäfer, a physical chemist at the University of Arkansas, says that: "In the empirical world only that which can be proven is true. But according to quantum chemistry, reality consists of forms, not of matter or energy, which is also true. Although non-visible, they are in every single molecule, like a wave factor or condition factor. These virtual events are patterns of information, with an innate ability to view them in the empirical world.

Physical reality thus arises in two areas - as proof and as shapes of potentiality. To prove the existence of the virtual forms, methods of so-called proven experience do not work. It does not have access to the trans-empirical, that which is 
beyond our experience. Measurement and the evidence of physical things is not enough because the empirical cannot show us all of reality, as it is."[33]

\subsection{Toward a Science of Consciousness}

At Toward a Science of Consciousness (TSC) in Arizona in April 2014, I presented my theory in a Poster Session where Deepak Chopra showed up and spent some time studying it. Finally, he said, "I totally agree!"[34]

There was also a visitor who didn't agree with the idea of interdependence of time and place, referring to an experience of visiting a haunted house. Disappointed leaving the house as nothing had occurred, suddenly she saw in front of her the image of a stampeeding herd of cattle. There was a frightening sound and she rushed towards her car for protection but felt that the herd knocked her to the ground. Though it had run straight through her, as it was imaginary, she said, "there was a time and a place where this happened." I tried to explain that her example was perhaps evidence (though anecdotal) of time and space not being applicable to transpersonal experiences of this nature. If it was true, it showed that a transpersonal event might occur independently of actual time and space. Although she believed in ESP phenomena, she could not grasp the essential conditions needed to enable something like this to happen. It reminded me of a discussion with another believer who said, "I do not care why or how it is; I know it is." Although such a view is of little use to a researcher with a scientific interest, it is of course necessary to accept such a view of reality. Meanwhile, discussions are ongoing on hard and soft facts and quantum or mathematical computations, as if such calculations were to make consciousness more understandable. Einstein may have been on track in suggesting that consciousness is beyond space and time; that is enough to open up to explanations other than physical and mathematical.

At the fourth day of TSC conference there was a plenary called "Time and Consciousness" dealing with precognition without saying the word as if it was taboo. Soon after the lecture there was a bus excursion into the mountains that many of the participants missed and also the speaker Julia Mossbridge. She talked with her husband on the phone and complained about the situation and I overheard his answer. "Believe me You will not want to be on that bus!" Later on another bus also heading to the mountain to the restaurant were we all would gather I heard in my mind "it will burn and crash" not knowing if it was only imagination. Suddenly I became worried about JP, one of two friends that were on the sightseeing bus and I told this to the passenger TLF next to me. Later we found out that the sightseeing bus had crashed into the corner of a house and that a long metal object had run throw the window and almost hit JP. Then the brakes of the replacement bus burned so all passengers were exposed to a life threatening danger and they decided to step of and wait for a new bus. Although this had happened and being verified it was considered to weird to discuss in the Conference. The possibility of precognition is still controversial among sceptics an experts focused on "brain consciousness" as if the brain was locked in physical perception and calculations of these perceptions.

On the last day of TSC, the results of two studies were to be presented: the AWARE study and the Rat study. Both projects were intended to contribute research on the phenomena of near-death experiences (NDE). I was sceptical of both, the $A W A R E$ study because I thought its design was, if not impossible then extremely dubious, while the rat study is certainly not about NDE. Sam Parnia, responsible for the AWARE study, cancelled his lecture. The presentation of this project had really been the main reason for me to travel halfway around the world; obviously I was very disappointed. However, I still want to give the background to the AWARE Study and to my scepticism.

\subsection{The AWARE Study}

"The AWARE (AWAreness during REsuscitation) Study was launched by the Human Consciousness Project, a multidisciplinary collaboration of international scientists and physicians who have joined forces to study the relationship between mind and brain during clinical death, and is led by Dr. Sam Parnia.”[35]

This highly ambitious study to basically seek evidence of near-death experience was considered by many researchers in the field to have a plan and construction designed to fail. That was also my opinion. When I got the chance to meet Peter Fenwick, I asked him if any of the team behind the design had had an NDE; he said with great certainty that none had. I questioned the design and could understand the reason for the supposed failure. I also understood that the team had not established what was required for a successful design. Their method had been to put computer screens on a shelf in a room where one could expect patients could be revived after cardiac arrest. These screens showed random pictures which a revived patient might have seen and could then have been able to describe. The AWARE study has not presented any substantial NDE results so far even though almost 5 years have passed since the team promised to publish its results.

\subsection{The "Rat Study"}

Another study criticised for not understanding the concept of NDE is what has been called "the infamous rat study."

A team of researchers at the University of Michigan have studied the brain activity of rats and claim they succeeded in measuring the brain activity when the rat dies. They claim also to have found the mechanism of NDE: "a surge of neurophysiological coherence and connectivity in the dying brain."'[36] This became a popular story under the headline: "Brains Of Dying Rats Yield Clues About Near-Death Experiences."[37] 
"Scientists praised the research, which appears in the Proceedings of the National Academy of Sciences." (Rob Stein) However, other scientists were unconvinced and less enthusiastic; they questioned how much rat brains could really tell us about human NDEs - if anything at all.

"I don't think that this particular study helps in any way to explain near-death experiences in human beings," says Sam Parnia, who studies dying and NDEs at the Stony Brook University School of Medicine in New York. "We have no evidence at all that the rats had any near-death experiences or that animals can have any such type of experience," Parnia says.

\subsection{The Hypothesis of an Existential Hub}

The hypothesis of an Existential Hub is in no way validated but is supported by neuro-scientist Professor Matti Bergström. An "existential hub" allows for various conditions and different states of consciousness. I assume that this hub coordinates dependent consciousness (dependent on a functioning brain) and independent consciousness that is independent of a measurably functioning brain. Bergström has confirmed at least part of the hub theory by what he calls Mandelbrot-Self. He identifies the same area as I have done and describes the possibility of the spiritual self that he equates with the existential hub. Bergström's premise is biological physical - mathematical. My starting point is psychological - biological - philosophical. I assume that an existential hub may be an interface between the central senses (ECO centre), the dependent and independent senses and thus the mind-body or soul. In the living, healthy brain there are dependent senses that prevail but in a damaged brain or one in a comatose state, "independent senses" can, independent of body senses, take over.

\section{Discussion}

My theory may be regarded as differing from Dr Larry Dossey's theory of "One Mind" if my suggestion of three consciousnesses should be looked upon as atomistic. I don't regard them as separate but interlinked. In "A Boundless Consciousness," an interview by Richard G. Young (2002), Dossey explains his views: "Mind (mentality) and consciousness (awareness) are fundamental and cannot be broken down or explained as parts. An atomistic perspective entails understanding the context in parts' properties. A holistic approach means that the whole is greater than the combined parts. The context for a part does not cover the whole." Dossey earlier opposed attempts to understand consciousness as energy: "That metaphor is absolutely terrible! Consciousness does not behave like energy! It is completely independent of the spatial de-markation. It can also slow down and restrict all forms of known energy. Consciousness cannot, however, slow down."
Dossey today accepts energy as a metaphor but nevertheless does not have the restrictions of energy.

Perhaps my idea of this is coming from a different point of view. Dossey has run research from a scientific perspective at a hospital. I have experienced a car crash and its implication on my body and mind and also experienced transpersonal phenomena in conjunction with the crash. My reflections on this are that there can be at least three kinds of consciousness. I even think that independent consciousness has a state of super-mind that can observe what happens in the body and the results of decisions made by the brain.

\subsection{Assumption about "Body Consciousness"}

To consider the "ECO senses" as modalities may belittle them, as I see them as the possible original senses of the body. How can we explain the five established physical senses evolutionarily unless there is something that they have evolved from? Body memory is a hypothesis that the cells of the body itself are capable of storing memories, as opposed to only the brain. Also here we can see sign of wikipedia sceptics denying this subject calling it pseudoscientific especially when it comes to the subject of memories of incest or sexual abuse. While professionals working with the body, rehabilitation physiotherapists and scientists studying body awareness consciders body memory not only plausible but a reality worth exploring. [38] If we assume the possibility of cell intelligence and taking into consideration that cells have a memory that allows for proper reconstruction of organs and muscles, we can also assume emotions and traumas affect these cellular memories [39] and even effect the recipient of organ donor to the degree that it might influence the personality. [40]

\subsection{Assumption about "Brain Consciousness"}

René Descartes proposed the notion "I think, therefore I am", the idea that the mere act of thinking proves a consciousness. Descartes also proposed a mind separate from the physical body, a concept known as mind-body duality. In neuroscience, much has been learned about correlations between brain activity and subjective, conscious experiences. In contemporary science there is a belief that neuroscience will ultimately explain consciousness. Eric Kandel promotes "In Search of Memory: The Emergence of a New Science of Mind" (2007): "...consciousness is a biological process that will eventually be explained in terms of molecular signalling pathways used by interacting populations of nerve cells..." This view emphasizing a biological and materialistic perspective argues that chemical processes are all there is. During the last century, the brain has been the subject of Brain-mapping. In what part of the brain are the functions of perception and various abilities located and how do they interact? Another view on consciousness use mathematical 
explanations some trying to "measure mind" chasing "An intelligence based materialistic explanation to evolution". There is also an ongoing philosophical discussion where Quantum physic is a popular base for theories. The philosopher David Chalmers known for the idea of soft and hard problems has argued against quantum consciousness. $\mathrm{He}$ is skeptical of any new physics to resolve the hard problem of consciousness. It is interesting that when John B. Watson as a representative of behaviorism claimed that the mind is immeasurable, it's a completely different starting point than that of Rollo May and humanistic psychology. Behaviorism conception of mind as an impenetrable black box and accompanied by opportunities to control the thoughts and manipulate the behavior stands against humanistic psychology openness to a holistic approach to human existence and spirituality. It emphasize the view of the "whole person" greater than the sum of our parts and takes a stand against minimizing a person as statistics of thoughts and behaviour. Humanistic psychology is based on the understanding of how emotions affect the living being and also the spiritual connection of life and death. It is developed into the field of transpersonal psychology defined as "experiences in which the sense of identity or self extends beyond (trans) the individual or personal to encompass wider aspects of humankind, life, psyche or cosmos". [41]

\subsection{Reflection on NDE Studies}

How can the two NDE-studies mentioned earlier be examined in the light of science, design and ethics? What unites them is that their design is based on science technology. What distinguishes them is that the "Rat study" is believed to be able to measure the moment of the NDE by recording brain activity using technical measuring equipment.

The AWARE study seeks to capture the moment for an out of body experience (OBE). The condition is that the revived patient should be able to provide feedback about a randomly displayed image from a computer screen atop a shelf near the ceiling.

Having had an NDE, you would consider a design such as this to be next to useless. During a near-death experience, as I experienced it, the interest is solely directed towards one's own body and the people linked with it, rather than meaningless technology on a shelf. So, in my opinion, the likelihood of anyone noticing a screen is very small.

The Rat study tells us nothing about NDE experiences. It provides only technical information about an electrical change in the brain at the moment of death. The experiment contains within it several problems. First, there is just the physical registering of brain processes during the moment of death. Also, there is no possibility of a revived rat being able to communicate any kind of information. These experiments on animals, regardless of anything technical, biological or behavioural, are totally irrelevant. The fact that the rat's brain activity increases at the moment of death has nothing to do with an NDE but rather with a collapsing brain. The only thing they have possibly found is the electrical activity at the moment of death.

Any discovery brings with it a range of problems. The physical registration of brain processes during the moment of death is not an NDE. To begin to understand an NDE it is important to obtain the perceptions of the person who has returned to life. Trying to communicate with a rat resurrected from death would be of no value, as the rat could not pass on information (unless one uses a rat whisperer!)

The multitude of reports of near-death experiences indicate that an NDE not only demonstrates a consciousness that works when an individual is in a coma but even when no brain activity can be recorded.

Doctors' reports give examples of anaesthetised patients who can accurately report details of what happened while they were unconscious, with the brain inactive. On waking, they could tell what the people around them had said and done during their period of unconsciousness. Many have even been able to tell what has happened outside the room. The patient should not have been able to perceive anything yet had observed everything.

"There are enough case studies to provide support that consciousness has a parallel 'independent existence' independent of the living body." (Holden, Greyson \& James, 2009)

Chris Carter, who has studied NDEs, argues that: “... consistent, reproducible evidence already presented. If this was any other field of scientific compilation, the data presented would have resolved any doubts decades ago."

\subsection{Reflection on Eventual Premonition}

In relation to the canoe event: I suggested that when she talked to her friend to see if she had plans to canoe alone in the archipelago, this could be regarded as a harmless question; she could have rejected the information and chosen to have her canoe holiday anyway. I am ambivalent about having influenced a stranger to get her to change her mind and perhaps her whole life. The coincidence is nevertheless strange. There are too many accurate statements to simply call it "random." I chose to assess it as information to pass on; then it is up to the individual to decide what is reasonable. In retrospect, I am not sure if it was precognition as it could have been a message from her deceased father; he had stepped forward when I seemed reluctant to relate the vision. He was worried about his daughter and did not want her to go out alone in a canoe. If it was a message from the other side, it is no less remarkable.

A description based on established physical senses is not enough to explain consciousness, communication and creativity. In what way do we receive messages and how do we "filter" such messages and our responses? How is it that we miss things that happen around us? Why is it that we sometimes do not react to an "alarm" yet sometimes to the smallest signal? Perhaps there are several answers. We may not want to respond to something that seems too difficult and 
so deny it. However, when we do not put up emotional barriers to a signal, it can be noticed immediately. So far, I have not found any studies on this, but draw conclusions from personal experience.

\subsection{Assumptions about Independent Consciousness}

I wanted to try to understand the experience that I had when I almost died. How was it possible to see your own body from an elevated position? It took several years before I found studies on the concept of near-death experience (NDE) and out-of-body experience (OBE).

Research on NDEs provides circumstantial evidence for what is called spirit, soul, astral body or mind-body, in the sense that it is an entity that exists and communicates regardless of physical life. A mind-body seems to be able to see, hear and perceive the environment even though the brain has been diagnosed as clinically dead. Based on this background, the following assumptions are made about the independence of consciousness, NDE evidencing an "independent mind" (IM):

- IM can use different hierarchical senses

- IM can perceive even if physical senses are not functioning

- The laws of nature, time and space do not govern an IM

- IM can communicate with other IMs

- IM is not dependent on the brain and does not register biologically or physically.

Einstein's belief in an undivided whole reality was so obvious to him that he rejected the time separation of what we experience as the moment "now." He believed that there is no real distinction between past and future: it is, rather, a single existence. His most descriptive testimony to this belief came when his friend Besso died. Einstein wrote a letter to Besso's family, expressing the fact that although Besso had preceded him in death this lacked significance "... because we physicists believe the separation between past, present and future is only an illusion, though a convincing one."

What Einstein describes is a dimension of consciousness that became available to him in such a convincing way that he tried to explain it in mathematical terms. In my imaginary world, physics and string theories are no longer plausible. One way to avoid having to worry about the quantum and mathematical models of explanation is to regard consciousness as a single supreme and call it cosmic consciousness. However, in order to understand consciousness, we must also accept that there are degrees of consciousness that are unique to each individual. This means that there are as many minds as there are individuals.

There is also probably a shared consciousness and I am not referring to Jung's "collective unconscious" which refers to structures of the unconscious mind populated by archetypes, and instincts that are shared among humanity and perhaps even all living creatures of the same species.
The possible experience of a common consciousness is nevertheless unique and has an individual and personal aspect. The availability of this common consciousness should be affected not only by the perception of the external world but also by how we perceive and reflect signals, and on the experience of this inner "invisible" world that connects us with each other both physically, as living individuals, deceased, nature and possibly even the universe. The scope of this is so tremendously overwhelming that it is impossible to fully understand and explain. However, this should not prevent us from trying.

In 1991, in an interview with Dr. Larry Dossey [42], Betsy Whitfill asked his views on the soul and the issue of non-local consciousness. Dossey has borrowed the term "non-local" from physics; he postulates the idea of the "non-local" mind. Dossey submits in his book "Recovering the Soul," evidence that a part of the mind defies space limitations and is basically the creator of reality.

Dossey: "The mind as defined in the 'local mind' model used by [natural] science is considered to be just the result of the anatomy and physiology of the brain. It [awareness] is fixed in space and localised in time [what I call elemental consciousness]. According to this model, local minds do not wander about [this sphere]; they stay fixed and in place in the present moment. It is an individual and isolated 'me,' I and no-one else. The non-local model is none of these. It is not confined in space and time to the brain and body, although it may work through the brain and body. And it is not confined to the present moment. Infinite, and by [logical] inference, immortal, eternal, omnipresent - all of these are consequences of anything that is non-local, not just mind. As a result, if mind is non-local, there is one mind, or Universal Mind, which is identical to what the West regards as the Soul.

Nick Herbert wrote a book "Quantum Reality," for lay people. In non-mathematical terms, Dr Herbert describes the world as essentially non-local. "It may be hard to imagine but physics experiments have clearly shown that non-locality is the characteristic of the world at the sub-atomic level. Bell's Theorem has proved this. Non-locality is at home in physics and since physics is the most accurate science we have ever had, we are justified in using the term to describe a similar state of being at the level of mind." (End Quota Dossey)

For almost a year during 2013, I discussed this term "non-local," and other issues, with Dr Dossey. I believe that we have a consensus regarding "non-local" and "Independent" mind. In the award-winning book "One Mind" (2013), Dossey develops these ideas further. [43]

There is a similar explanation from Dr Peter Fenwick in an interview 2013 I asked: "What is the most exciting thing about the brain?" Peter answers: "It's not really the brain itself that's exciting, although of course the wonderful complexity of the brain's mechanism and architecture is totally fascinating. For me, the really exciting fact is that it appears to be the gateway to consciousness." This gateway 
might be what I call the "existential hub."

In seeking the Existential Hub, I suggest that there might be a consciousness connecting Body, Brain and Psyche (Spirit) i.e. the theory of three different minds, all inter-linked. The first is "body consciousness" that originates within the body. We all sense when the body "tells" us how it feels, what it lacks and what it wants. Then there is "brain consciousness." This is dependent on the "health" of the brain; in dementia, we lose memory and the ability to deal with even the simplest tasks. The interaction of mental trust and emotional self-confidence can cause the body to increase its performance, while negative stress can prevent the functioning of both brain and body. A strong impression retained in the consciousness will be experienced emotionally and will usually result in physical expression and reaction. To support the hypothesis of body consciousness and the significance of the heart, there are a number of studies of heart transplants. These testify that people can undergo fundamental changes of personality and suddenly acquire new interests and tastes. These changes can be traced back to the donor. The search for an "existential hub" does not end with the "heart-brain" connection. Reports suggest that the mind also has its own external level, existing and functioning outside both the body and the brain. I call it the "independent consciousness." Former Research Director Dr Larry Dossey calls it "non-local."

This independent consciousness becomes apparent during out-of-body experiences (OBEs) and near-death experiences (NDEs), especially when the brain has been declared clinically dead or is in a coma. People who have returned to life from such conditions may tell of the most outstanding impressions, even how doctors and nurses have acted during a patient's "unconsciousness" or "death". However, the person has not been totally "unconscious;" the brain has been turned off, the brain consciousness shut down, though another, much sharper, "independent consciousness" has been present.

This raises the question of how independent consciousness interacts with the body and the brain. Is there an existential hub? The independent consciousness may capture images of its "dead" body and the thoughts and feelings of this body, even if it is on the other side, in the so-called spirit world. This means that there is a consciousness that we cannot yet explain or understand using the laws that are applicable to Natural Science and its guidelines to describe and create the boundaries of reality.

Independent senses of perception vary within and amongst individuals. Some seem to lack such senses entirely, while others are more or less receptive. It should not be confused with intuition, to which all have access, or to guidance based on knowledge and experience, as Dreyfus and Dreyfus explain it. [32]

\section{Conclusions}

My research started from an urge to find an explanation to mystical experiences in connection with a car crash. At first, it led to adoption of the ideas of a possible "body-consciousness" and "brain-consciousness" and then to find explanations of psychic experiences that led to the adoption of an "independent-consciousness." Furthermore, I needed, as a sceptic, evidence and theories. In this hunt for knowledge, I found studies of near-death experiences that I regarded as promising evidence for an "independent consciousness" (independent of organic life, thus independent of a functioning brain and, above all, independent of a physical living body). In early 2000, such studies were not to be found on Yahoo or Google. Consequently, I could define its content and significance. What serious NDE research shows is that there are minds and a consciousness that is running when the brain is disconnected. NDEs also indicate that there is a soul or a mind-body that can move freely and meet other minds, both living and dead. It provides evidence for life after death.

So, in parallel with pointless rat studies in the science of biology, there is a genuine desire in human science to explore this field, although not always using an appropriate design.

The search for understanding my transpersonal experiences began with documenting them and trying to find natural causes and explanations. It led to consideration of the origin of being. If there is life there is also consciousness and, having had a near-death experience, I came to the conclusion that life is dependent on consciousness but consciousness is not dependent on life.

It seemed to me that life-forms were a result of, or rather an expression of, such independent consciousness as if a seemingly chaotic mind delegated each being to form itself and also develop itself throughout evolution. This means that "free will" is a gift of God, metaphorically expressed. However, since brain consciousness is so slow compared to body and independent consciousness, it sometimes seems that life has limited free will.

Having had an NDE, you might also be quite certain that there is no Master on the other side demanding anything of you or judging you for your shortcomings. On the contrary, life is a case of "trial and error" or, as I like to put it, "try again" and an afterlife gives an opportunity to reflect upon it.

The interaction of a (spiritual) mind-body and living body can consciously use thoughts and emotions to influence physical health. "The natural healing force within each one of us is the greatest force in getting well." (Hippocrates)

When the self-healing placebo mechanism is enabled for a specific problem, it seems to be enabled more quickly. Thus, the ability to heal oneself is tied to body consciousness and the emotional and mental capacity of the brain. Sometimes an Independent Mind may come in handy and promote healing.

Clear sense (clairsentience) includes, at a mediumistic level: clairvoyance, remote viewing, clairaudience, clear odour and clear taste, all of which involve the ability to perceive impressions that lie beyond the bounds of normal 
physical senses.

Mediumistic perception can obtain information not initially understood but which becomes clear when something occurs that explains the information. Independent minds can also involve anything from telepathy to clairvoyance. Since it can easily be confused with imagination, it is quite normal to take a sceptical approach to such phenomena.

This proto-scientific study of a theory of mind and consciousness is challenging and asks many questions which still need to be answered. Therefore, further research to prove the validity of the theory is necessary.

\section{Acknowledgements}

I am very grateful to Professor Adrian Parker, Dr. Larry Dossey and my wife and partner Ritva Peratt for their relevant and constructive suggestions in discussions of this content. I also thank Mayne Sundewall-Hopkins and David Hopkins for support and proof-reading to improve this paper.

\section{REFERENCES}

[1] B. Peratt, Succébo, On Origin of Consciousness Part 1. Visam $\mathrm{AB}, 2011$

[2] B. Peratt 12 Sinnen, On Origin of Consciousness Part 2. Visam AB, 2011

[3] L-E Uneståhl Ph.D., 50 years with Integrated Mental Training, SVEBI (Swedish Association for Behavioural and Social Research in Sport), Scandinavian International University, 2001. ISBN 2001-6018

[4] Bin He, Brain Cap Research: Thinking Things Through, University of Minnesota, 2013

[5] Arton G. Webster, The Physical Laboratory and its Contributions to Civilization, p 168, The Popular Science Monthly, 1914

https://www.google.com/search?q=emotion+disturbing+fact or + science \&ie $=$ utf- $8 \&$ oe $=$ utf- 8

[6] R. W. Sperry, "Cerebral Organization and Behavior: The split brain behaves in many respects like two separate brains, providing new research possibilities." Science 133 (3466): 1749-1757. doi:10.1126/science.133.3466.1749 (1961).

[7] C.R., Cloninger, D.M., Svrakic, T.R., Przybeck A psychobiological model of temperament and character. Arch Gen Psychiatry. 50(12): 975-90. (1993)

[8] S.L. Glashow, J. Iliopoulos, L. Maiani. "Weak Interactions with Lepton-Hadron Symmetry." Physical Review D 2 (7): 1285. Bibcode:1970PhRvD. 2.1285G. doi:10.1103/PhysRevD.2.1285 (1970)

[9] Weizmann Institute of Science. "Quantum Theory Demonstrated: Observation Affects Reality." Science Daily, 27 February 1998. www.sciencedaily.com/releases/1998/02/980227055013.htm

[10] Hacking Into Your Happy Chemicals: Dopamine, Serotonin, Endorphins and Oxytocin. HuffPost, 20 Oct 2014.< www.huffingtonpost.com/thai-nguyen/hacking-into-your-ha ppy-c_b_6007660.html>

[11] John Grandy. International Journal of Arts \& Sciences, 2011. ISSN: $1944-6934:: 4(20): 7-30$

[12] Sondra Barret $\mathrm{PhD}$, medical scientist with a degree in biochemistry from the University of Illinois Medical School and post-doctorate training in immunology and hematology at the University of California Medical School. "Secrets of Your Cells: Discovering Your Body's Inner Intelligence, 2013. ISBN-13: 978-1604076264

[13] G. Albrecht-Buehler, R. Laughlin "The Functional Anarchy of Genomes." European Academy of Sciences, Brussels, 2006

[14] G. Albrecht-Buehler, R. Laughlin, Fellow, Institute for Advanced Studies, Berlin. Northwestern University Medical School, Chicago Online Available:

http://www.basic.northwestern.edu/g-buehler/genomes/geno me.htm

[15] Larry Dossey. Reinventing Medicine: Beyond Mind-Body to a New Era of Healing. ISBN 0-06-251622-1 First HarperCollins Publishers Inc, 2000

[16] Michael Samuels, Mike Samuels, Mary Rockwood Lane, Shaman Wisdom, Shaman Healing: Deepen Your Ability to Heal with Visionary and Spiritual Tools and Practices, WILEY, 2003

[17] Witness Lee, The way to carry out the vision, p. 21 Living Stream Ministry. ISBN 0-87083-11-X, 1985

[18] Jill Bolte teaches at Indiana University School of Medicine and is a spokesperson for the Harvard Resource Center (Harvard Brain Bank). She has appeared on Oprah. TIME Magazine named her one of the 100 most influential people, $2008<$

http://personalityspirituality.net/2010/04/13/dr-jill-bolte-taylo r-the-neuroscientist-who-had-a-stroke-and-discovered-nirvan $\mathrm{a} />$

[19] Eben Alexander, Proof of Heaven: A Neurosurgeon's Journey into the Afterlife, Simon \& Schuster, 2012

[20] Oliver Sacks, Musicophilia: Tales of Music and the Brain, Knopf (2007), ISBN 1-4000-4081-7

[21] 'Musicophilia' and comparison with 'Ohma' published on project: On the Origin of Consciousness, 2015 https://ontheoriginofconsciousness.wordpress.com/2015/02/ 10/musicophilia-and-comparison-with-ohma/

[22] A Bolt from the Blue: Sudden Musicophilia http://www.newyorker.com/magazine/2007/07/23/a-bolt-fro m-the-blue

[23] Jung's Explosive Visit to Freud. Available online: https://www.psychologytoday.com/blog/untangling-lifes-co mplexities/201109/jungs-explosive-visit-freud

[24] Project Alpha was an elaborate hoax that began in 1979 and ended with its disclosure in 1981. The stage magician and Skeptic James Randi orchestrated it. It involved planting two fake psychics, Steve Shaw and Michael Edwards, into a 
paranormal research project. During the initial stages of the investigation, the researchers came to believe that the pair's psychic powers were real. However, more formal experiments, as well as criticism from the parapsychology community led them to discard their initial trust. The hoax was later revealed publicly. http://www.paranormal-encyclo pedia.com/r/james-randi/project-alpha.html

[25] William J. Broad. "Magicians effort to debunk scientists raises ethical issues." New York Times Science, 1983 http://www.nytimes.com/1983/02/15/science/magician-s-eff ort-to-debunk-scientists-raises-ethical-issues.html?pagewant ed $=$ all

[26] Quote by H E Puthoff, PhD. Lyn Buchanan who participated in the Stargate project as a remote viewer and calls this sense "the seventh." (Seventh Sense, 2003) http://www.biomindsuperpowers.com/Pages/CIA-InitiatedR V.html

[27] B. Peratt Succébo - fröet till framgång [\$uccébo - The seed of success], Visam AB, 2011 https://ontheoriginofconsciousness.wordpress.com/2012/05/ 25/uccebo-the-seed-of-success/

[28] B. Peratt. Blogg article ,"In the beginning ..." https://ontheoriginofconsciousness.wordpress.com/2012/05/ 24/in-the-beginning/

[29] Vetapedia, Oberoende medvetande http://vetapedia.se/oberoende-medvetande/

[30] John Searle "Searle: it upsets me when I read the nonsense written by my contemporaries, 2014 http://www.newphilosopher.com/articles/john-searle-it-upset s-me-when-i-read-the-nonsense-written-by-my-contemporari es/

[31] Dr. Bruce Greyson: Consciousness Independent of the Brain (2014) Youtube:

https://www.youtube.com/watch?v=en-3Bz1RMig

[32] Hubert L. Dreyfus and Stuart E. Dreyfus. Mind over machine: The power of human intuition and expertise in the era of the computer: Basil Blackwell, Oxford, 1986

[33] Lothar Shäfer. Infinite Potential: What Quantum Physics Reveals About How We Should Live. Deepak Chopra Books,
2013

[34] B. Peratt. "TSC Poster Session Wednesday April 23 personal diary." On the Origin of Consciousness, 2014 https://ontheoriginofconsciousness.wordpress.com/2014/04/ 24/tsc-poster-session-wednesday-april-23-personal-diary/

[35] S. Parnia, P Fenwick et al. The AWARE Study, Human Consciousness Project. Available online: http://www.horizonresearch.org/research-zone/aware-study/

[36] J. Borjigin Et al. Surge of neurophysiological coherence and connectivity in the dying brain. Pub Med. (2013) Available online: http://www.ncbi.nlm.nih.gov/pubmed/23940340

[37] R. Stein. Brains of Dying Rats Yield Clues About Near-Death Experiences. (2013) Available online: http://www.npr.org/se ctions/health-shots/2013/08/12/211324316/brains-of-dying-r ats-yield-clues-about-near-death-experiences

[38] Rehabilitation Science (Physiotherapy) MSc (PGCert PGDip) University of Brighton https://www.brighton.ac.uk/courses/study/rehabilitation-scie nce-physiotherapy-msc-pgcert-pgdip.aspx

[39] Susan Cosier, Could Memory Traces Exist in Cell Bodies? Scientific American. (2015) http://www.scientificamerican.c om/article/could-memory-traces-exist-in-cell-bodies/

[40] Lizette Borreli, Can An Organ Transplant Change A Recipient's Personality? Cell Memory Theory Affirms 'Yes', Medical Daily, 2013

http://www.medicaldaily.com/can-organ-transplant-change-r ecipients-personality-cell-memory-theory-affirms-yes-24749 8

[41] Walsh, R. \& Vaughan, F. "On transpersonal definitions". Journal of Transpersonal Psychology, 25 (2) 125-182, 1993

[42] B. Whitfill: Recovering the Soul. Interview with Dr Larry Dossey: issue of Share International. Dr Larry Dossey is a physician of Internal Medicine, formerly Chief of Staff of Medical City Dallas Hospital, 1991

[43] L. Dossey, One Mind -How Our Individual Mind Is Part of a Greater Consciousness and Why It Matters, HayHouse, 2013 